\title{
Two decades of inquiry-oriented learning in first year undergraduate physics laboratories: an Australian experience
}

\author{
Les Kirkup
}

\begin{abstract}
A review of the first year physics laboratory program in 1991 at the University of Technology, Sydney (UTS) revealed that student laboratory experiences did not: resemble the practice of physicists; give a realistic picture of the contribution of physics to everyday life, or; enhance students' capabilities of broad value, such as their communication skills. Physics academics at UTS committed themselves to reforming students' laboratory experiences with inquiry-oriented learning as a centre-piece of the reform. This chapter explores the drivers that led to the reconceptualization of the role of the laboratory in the undergraduate curriculum and the strategies and processes we adopted over more than 20 years to embed inquiry-oriented activities into first year physics laboratory programs.
\end{abstract}

\section{Introduction}

There is renewed emphasis on enhancing student learning in science through having students engage in the processes of inquiry (Etkina, Karelina, Ruibal-Villasenor, Rosengrant, Jordan, \& Hmelo-Silver, 2010). This emphasis is evident through the stress placed on science inquiry skills in years K-12 of the Australian Science Curriculum (National Curriculum Board, 2010) and at tertiary level through the central place of inquiry and problem solving in the Australian Science Learning and Teaching Academic Standards Statement (Jones, Yates, \& Kelder, 2011).

It has been recognised for decades that the processes of inquiry should feature prominently in science education (Schwab, 1960). In criticising experiences routinely offered to students in an undergraduate physics laboratory, Bless (1933, p.89) remarked: 
Cookbook instructions certainly do not stimulate the student's capacity for reasoning or ingenuity. If anything, these are stifled under such a procedure....it is time to realise that the results [of experiments] are of much lesser importance than the process by means of which these results are obtained.

Experiments which rely on 'cookbook instructions' are highly guided, verification-type experiences or activities (Hegarty, 1978). Students follow detailed instructions in order to reach a well-defined, and often already well-established, end-point. Such experiments were the norm in first year physics subjects at UTS up to 1991. At that time academics in the Department of Applied Physics (DAP) at UTS began to realise opportunities were being wasted to enhance student engagement and learning through actively involving students in the processes of inquiry.

The importance of experimentation and the processes of inquiry in the science curriculum are reflected in documents of national status. For example, the American Association of Physics Teachers (AAPT, 1998) placed 'the art of experimentation' at the top of their list of the goals of undergraduate physics laboratories, expressed as :"The Art of Experimentation: The introductory laboratory should engage each student in significant experiences with experimental processes, including some experience designing investigations.” (AAPT, 1998, p. 483).

The AAPT elaborated on this goal: "Laboratory investigations should engage students in the process of formulating and asking an interesting question about nature. Students then select the methods and apparatus needed to make progress towards finding an answer." (AAPT, 1998, p. 484). 
This chapter describes factors that stimulated a major reconsideration of the first year physics laboratory programs at UTS and the approaches we adopted to revitalise those programs by embedding inquiry into experiments for three large enrolment first year physics subjects:

- Physics $1 \mathrm{C}$, taken by $\approx 150$ students/year majoring in chemistry, physics or materials science;

- Physical Modelling, taken by $\approx 600$ students/year majoring in engineering, and;

- Physical Aspects of Nature, taken by $\approx 650$ students/year majoring in the medical, biological or environmental sciences.

The reconceptualization of the laboratory program for Physics $1 \mathrm{C}$ acted as a touchstone for later developments of Physical Modelling and Physical Aspects of Nature. Accordingly, most attention is paid in this chapter to the redevelopment of Physics 1C.

\section{Review and development of Physics 1C}

In the early 1990s around 150 students enrolled in Physics 1C in their first semester at UTS. The delivery of Physics 1C consisted of, on average, 3.5 hours of lectures/tutorials each week for 13 weeks. Students, working in pairs, completed one experiment of 2.5 hours duration each week for 10 weeks. A laboratory group consisted of up to 18 students supported by a 'demonstrator' (equivalent to a teaching assistant in US universities). Each week, some students would be assigned a mechanics experiment, others an electricity experiment, and so on until over a semester they had completed their allocated experiments. They would typically carry out an experiment either well in advance or well in arrears of consideration of the relevant underlying concepts in lectures or tutorials. This represented a systemic disconnect between lectures, tutorials and laboratories that made up each first year subject. 
By 1991 several drivers encouraged the DAP to review the Physics 1C laboratory program. These drivers included:

- dissatisfaction with the 1991 laboratory program as expressed by students through anonymous surveys;

- faculty discontent with a laboratory program virtually unchanged for more than a decade;

- a determination to critically review the purpose and delivery of first year laboratory programs prompted by consultations with teaching and learning specialists at UTS, and;

- the infectious enthusiasm of a head of department committed to reforming the laboratory experience of first year students.

At the heart of the reform of the Physics 1C laboratories was the simple question: what do we want students to get from laboratory work? To address this question we assembled a 12 member working party (WP) consisting of physics academics, demonstrators, technical staff, educational researcher and an educational developer.

As we explored this question, it emerged that many facets of laboratory work we valued as practicing scientists, such as opportunities to discuss findings with peers, were absent from the laboratory program. The WP members reviewed the experiments and made judgements as to whether a student, as a result of carrying out experiments in the program, would have to (Gosper, Cheary, Hazel, \& Kirkup, 1993):

a) engage in scientific inquiry by exploring a phenomenon, developing a procedure, or designing an apparatus;

b) demonstrate experimental skills or use an instrument or device; 
c) use data reduction skills such as graphical or error analysis, and;

d) demonstrate enhanced physics knowledge by doing the experiment.

Of the 14 experiments reviewed, $100 \%$ satisfied b) and c) above. Only $21 \%$ of the experiments required exploration. None required a student to design an apparatus or develop a procedure, and only $7 \%$ required students to demonstrate enhanced physics knowledge.

The next stage of the review examined the openness to scientific inquiry of each experiment using the scheme illustrated in Table 1, adapted from Boud, Dunne, and Hegarty-Hazel (1989). The table relates the level of scientific inquiry inherent within an activity to the extent of student autonomy.

\section{TABLE 1 SHOULD APPEAR ABOUT HERE}

An experiment in which students follow instructions to reach an outcome or answer that is already known, is classified a level 0 experiment. At the other extreme, a level 3 experiment is one in which the students devise the aim, the means by which the aim will be achieved, and are responsible for advancing and defending their answer. Patently, student autonomy and responsibility increase as the level rises from 0 to 3. Of the experiments reviewed, $14 \%$ (2 experiments) were classified at level 0 and $86 \%$ (12 experiments) at level 1. No experiments were classified by the WP at level $2 \mathrm{~A}$ or higher.

Feedback from student questionnaires about the Physics 1C laboratory in 1991 indicated that students were preoccupied with the technical requirements of an experiment with little time for, or consideration of, design, analysis or inquiry. These findings, along with an extensive review of the 
laboratory program by the WP, led to the conclusion that the 1991 laboratory program (Gosper et al., 1993, p. 9):

was unlikely to enhance students' interest or sense of excitement about physics, unlikely to help motivate students to continue physics studies at a higher level, unlikely to help develop positive attitudes to science or build scientific literacy. Moreover, the laboratories offered an inaccurate picture of physics and its relevance to everyday life.

The WP committed to reform the Physics 1C laboratory program with the aim of making it more stimulating, personally involving and relevant to student lives. Educational research (Welch, Klopfer, Aikenhead, \& Robinson, 1981) offered evidence that an inquiry-oriented approach could accommodate those aims as well as expose students to experiences such as curiosity, perseverance, experiencing failure and dealing with doubts (Tamir, 1983). The development of the new program drew on the constructivism theory of learning. According to this theory, students create meaning through investigation and engagement often within real world contexts (Lee, 2011). Beyond this, the WP agreed that a new program should offer students opportunities to engage in activities that closely imitate those of practicing scientists. The program recognised that students use prior knowledge to make sense of new information and situations and that meaningful contexts and relevance are keys to student engagement (Ramsden, 2003).

All the experiments within the 1991 Physics 1C laboratory program were set aside and new experiments devised. Six experiments were developed with inquiry as a central theme (Gosper et al., 1993; Cheary, Gosper, Hazel, \& Kirkup, 1995). Classification of the experiments using Table 1 indicated that one experiment was at level 1, with the others at level $2 \mathrm{~A}$. The new 
experiments were trialled with students in 1992 and evaluated through staff and student interviews and surveys.

In the revised laboratory program, all students carried out the same experiment in the same laboratory session allowing the experiment to be sequenced with the lectures. It was observed that students working on the same experiment at the same time stimulated meaningful discussions and comparisons of the various approaches adopted.

\section{Student Assessment}

The WP recognised that the emphasis brought to inquiry, experimentation, and communication must be reflected in the assessment scheme for the laboratory program. Prior to the development of the post 1991 laboratory program the assessment items were: i) a formal report of one of the experiments carried out by the student during the semester, and; ii) an end of semester practical exam in which students performed an experiment then wrote it up during the exam. A diverse assessment scheme was implemented for the Physics 1C laboratory program, consisting of:

- Compulsory prework to be completed ahead of the laboratory. The prework might involve a take-home kit which students use to carry out simple experiments in order to become familiar with some concepts and experimental challenges that feature in the experiment it supports;

- A skills test in which students work individually, requiring students critique a section of a report, perform data analysis and carry out a hands-on experiment (categorised as level 1 using Table 1).

- Examination of a student's laboratory notebook in which a student makes a contemporary record of their ideas, experimental design, data, calculations, difficulties, findings and 
tentative conclusion(s). This replicates a routine, but core, activity of professional scientists;

- A formal report requiring students to communicate their aim, methods and findings in a manner consistent with discipline norms, and;

- A poster and poster presentation. Students cooperate to present an experiment and its findings in a visual format used widely in conferences. Students fashion, present and orally defend their poster.

The variety in the student assessment components incorporated into the new laboratory program served to deliver a broader profile of student achievement than the program it replaced. To reflect the increased emphasis on laboratory-based activities, the contribution of the laboratory to the total assessment of Physics 1C grew from $15 \%$ to $25 \%$.

\section{Student reaction to the revised Physics 1C laboratory program}

Student reaction to the new approach was obtained through one-on-one interviews. The interviews were designed to establish students' experiences of the new program as well as the extent to which the program matched their abilities, background and anticipated future needs. Feedback from students included:

I find that (fewer instructions) are better than someone giving us the instructions and saying, do this and do that. If you have a problem you actually work hard at working it out and you feel you have accomplished something at the end. It's better than someone saying calculate this, calculate that.

(Gosper et al., 1993, p. 14) 
The new program brought an emphasis to formal and informal written and oral reporting within a supportive, small group laboratory. This was generally viewed positively by students: “The discussion helps to answer the questions that never get asked or answer the questions you wanted to ask and felt too stupid to ask.....Everyone benefits" (Gosper et al., 1993, p. 15).

Experiments in the post 1991 laboratory program emphasised the place of physics in the real world, in contrast to the largely context-free experiments which they replaced. A student repeating Physics $1 \mathrm{C}$ offered a comparison between the old and new programs:

It's giving a much better perspective about what physics is all about. When I started term this year I wasn't sure whether I was interested - but now that the course has turned out the way it has, I'm really enjoying it.

(Gosper et al., 1993, p. 16)

The revised Physics 1C laboratory program gave students more control over their experiences in the laboratory by allowing them opportunities to engage in inquiry. In doing so students participated in activities habitually carried out by practicing scientists which has been shown to promote positive attitudes towards science and enhance comprehension (Weaver, Russell, \& Wink, 2008).

The revitalisation of the laboratory program for Physics 1C students encouraged the DAP to revise the laboratory program for UTS engineering students required to enrol in the first year physics subject 'Physical Modelling'. 


\section{Review and development of Physical Modelling}

Our plan to reform our physics subject for engineering students called Physical Modelling occurred subsequent to a review of engineering education carried out by the engineering profession in Australia. An outcome of the review was a report entitled Changing the culture: engineering education into the future (Institution of Engineers, Australia, 1996) which articulated the desirable attributes of engineering graduates, including the ability to:

- apply knowledge of basic science and engineering fundamentals;

- communicate effectively, not only with engineers, but also with the community at large;

- undertake problem identification, formulation and solution.

It was against this backdrop that we revitalised the Physical Modelling laboratory program (Kirkup, Johnson, Hazel, Cheary, Green, Swift, \& Holliday, 1998). Supported by an internal UTS teaching and learning grant, a team consisting of physics and engineering academics, an educational developer, and several technical staff was assembled. An aim of the development was to bring a balance to laboratory work focussing on specific technical competences and more open activities relevant to engineers which foster independent learning, critical thinking and professional values.

Throughout the process of reform of the Physical Modelling laboratory program we canvassed a wide range of stakeholders. We identified, consulted and in some cases surveyed: first year engineering students, lecturers from the Faculty of Engineering at UTS, Engineering policy makers at UTS (including the Dean of Engineering, Associate Deans and Heads of School), senior committee members from the peak professional engineering body in Australia, namely the Institution of Engineers, Australia. 
One-on-one interviews took place with academics and engineering professionals. The interviews, which were audio-recorded, were typically of 30 minutes. They were then transcribed. Some of the interviews were face to face while others were carried out by telephone. We asked:

- Ideally, what qualities should undergraduate [physics] laboratory programs develop in engineering students?

- Which of these [qualities] could begin to be developed in a first year [physics] laboratory program?

An emphatic response that emerged from the consultations was that the laboratory program should put physics first and applications to engineering second (Kirkup et al., 1998). On the more specific matters regarding physics laboratory program and the qualities such a program might develop in students (Kirkup et al., 1998, p. 260):

[physics labs should develop] ability in problem formulation: thinking about equipment which might be used to address or explore the problem

Dean of Engineering Advisory Committee member, UTS

Student views on the existing laboratory program were sought through a questionnaire (Kirkup et al., 1998). Students believed the program could be enhanced by coordinating the lecture and the laboratory programs and that the experiments should be made more relevant to engineering and/or everyday life. The importance of sequencing lectures and laboratories was also recognised and commented upon by the engineering academics surveyed. As one senior engineering academic remarked (Kirkup et al., 1998, p. 260): "Surely in the early years lectures and labs should be sequenced - what do we think the students make of it otherwise?" 
Consultations with stakeholders, and consideration of the teaching and learning literature allowed us to frame a set of aims against which the revised laboratory program could be evaluated. We determined that the laboratory program should have relevance to students' professional development by: having an engineering perspective; experiments that relate to real world problem(s) or issue(s); encouraging the development of experimental design skills; needing careful measurements; utilising data analysis techniques; involving the comparison of models with experimental data, and; requiring students to engage in effective teamwork.

As with Physics 1C, we determined to infuse a strong inquiry-oriented focus into the Physical Modelling laboratory program. This led us to set aside the experiments that engineering students were required to perform up to 1996 . Up to 1996 the experiments were essentially recipe-based with no engineering context. Students worked in pairs with little opportunity to develop their own methods or discuss their results with other students. Post 1996, new experiments were created with an overt engineering slant that would be classified by Table 1 as level $2 \mathrm{~A}$ or $2 \mathrm{~B}$.

The redesigned laboratory program included:

- experiments with an engineering flavour;

- compulsory pre-work accompanying each laboratory session;

- time for students to devise and carry out their own experimental procedures;

- opportunities to describe their methods and results to the whole class in a semi-formal manner;

- experiments linked to and sequenced with, material delivered in lectures;

- larger units of work spanning more than one week, and;

- a diverse assessment scheme. 


\section{Evaluation of the Physical Modelling Laboratory program}

The laboratory program was evaluated using a student questionnaire and focus groups with engineering students. Details of the result of the questionnaire can be found elsewhere (Kirkup et al., 1998). Findings from completed student questionnaires included:

- Improved sequencing of the lab-based activities made a significant impact on students' awareness of the links between the material in lectures and the experiments;

- The introduction of experiments with engineering context enhanced students' perception of the relevance of the physics experiments to their engineering education;

- Students reported that the laboratory program assisted in improving their understanding of physics concepts and increased their interest in physics, and;

- The laboratory program increased students' confidence in doing physics.

The findings of the focus groups, which consisted of between 5 and 10 students chosen at random, largely supported the findings from the student questionnaires. Responses to the question 'What did you like most about the laboratory program?':

- "It was really exciting when we did things related to engineering, like the thermoelectric coolers."

- "I found it much better than previous labs, because before teachers would just tell us what to do and we would just do it. But here we would design our own experiments, get the results and use them, and that's much better." 
(Kirkup et al., 1998, p. 264):

Focus groups revealed that students valued the opportunity to engage in devising a practical solution to a problem that had meaning for them while being able to connect theory with practice. The readiness of students to grasp the opportunities that inquiry-oriented activities have to offer was highly variable between students. This is a situation familiar to those introducing inquiry in the laboratory at all levels of education (Wenning, 2005).

Successful revision of the physics laboratory programs for engineering students encouraged us to turn our attention to the physics subject called Physical Aspects of Nature which enrolled students intending to major in the medical, environment and biological (MEB) sciences at UTS.

\section{Development of Physical Aspects of Nature (PAN)}

A major re-development of the laboratory program for PAN which occurred post-2000 allowed us to integrate and apply what was learned developing laboratory programs for physical science and engineering majors. As with the development of the laboratory program for Physics $1 \mathrm{C}$ and Physical Modelling, the emphasis remained on students engaging in inquiry in contexts meaningful to them. The development team consisted of experts in pedagogy and other with firsthand experience of working with students in undergraduate laboratories. Views of a wide range of stakeholders were canvassed as the new program was developed and trialled. Successful elements from the development of Physics 1C and Physical Modelling were adopted, adapted and extended.

In 2007 we devised a framework to assist in the more systematic development and evaluation of individual inquiry-oriented experiments (Kirkup, Pizzica, Waite , \& Mears, 2012). The framework, which will now be described, is shown in figure 1. 


\section{FIGURE 1 ABOUT HERE}

In developing new experiments for PAN, we began by identifying topics that could form the basis of inquiry-oriented experiments. This occurred through attendance of a member of the laboratory development team at lectures given to first year students by faculty from the MEB sciences. This was followed up by one-on-one interviews with the lecturers. Such engagement allowed themes in the curriculum suitable for treatment through inquiry-oriented experiments to emerge that would be difficult to identify solely by inspecting paper-based or online materials provided to students. For example, attendance at lectures indicated that fluid flow was a theme of importance to students from the MEB sciences and so formed the basis of an IOL activity (Kirkup, Pizzica, Waite, \& Srinivasan, 2010);

Steps $1-4$, as shown in figure 1 , inform the development and improvement of the experiment through feedback. More specifically:

- In step 1, an academic trials the experiment considering its feasibility (for example with respect to time required to complete the experiment), the equipment requirements, and how the students should be prepared for the experiment (for example through carrying out a pre-laboratory exercise).

- In step 2 the written materials created to assist students in the laboratory are reviewed, not only by physics academics who could assure that the experiment is neither too demanding nor too trivial, but also by faculty from the MEB sciences. This allows faculty to advise on the relevance of the experiment to students majoring in their disciplines.

- In step 3, the experiments are trialled with a group consisting of students who have already completed PAN in an earlier semester and physics demonstrators not involved in the design of the new program. Students are paired with demonstrators to work on the experiment under the guidance of a senior demonstrator who was one of the developers of 
the experiment. Students and demonstrators are surveyed on the completion of the experiment and also take part in focus groups, and;

- In step 4, the experiments are rolled out to the target audience and feedback gathered through surveys and focus groups.

The framework in figure 1 promotes an informed and student-centred approach to the development and evaluation of laboratory-based learning activities. It reveals factors likely to affect student engagement allowing for timely intervention by the innovators. The framework promotes the accumulation of evidence about aspects of an experiment, for example whether students regard the experiment as enhancing their capacity to communicate in the laboratory. We learned through the application of the framework that professional development of demonstrators needed further emphasis if opportunities for enhancing student capabilities through inquiryoriented laboratory work were to be effectively exploited.

\section{Discussion}

\section{Drivers for change towards inquiry in the curriculum}

Calls for a greater emphasis on science students engaging in the processes of inquiry have grown over many decades (Tamir, 1983). While the impact on actual practices has been limited, a number of factors are acting to promote such engagement on a large scale in primary, secondary and tertiary education. Those factors include a shared commitment to promoting and embedding inquiry in the curriculum from national and institutional policy makers and those that engage directly with students on a day-to-day basis (Boyer, 1998). More specifically, the drivers for change include: 
- Senior figures, including Australia's Chief Scientist are vocal in advocating students be given insights into the processes by which scientific knowledge is created and challenged, by engaging in the process of inquiry themselves (Office of the Chief Scientist, 2013).

- Evidence accumulated over many years that active learning strategies increase student performance and enhance student critical thinking, written and oral communication skills and the capacity to work productively in groups (Hanif, Sneddon, Al-Ahmadi, \& Reid, 2009).

- The potential of inquiry skills to ameliorate the decline in STEM participation and arrest the attrition that occurs in STEM courses (Pitkethly \& Prosser, 2001).

- Finally, there is increased awareness that inquiry as carried out by undergraduates is able to imitate the research activities of practicing scientists and so is likely to gain favour with academics with a strong research orientation (Healey \& Jenkins, 2009).

\section{Making it happen: lessons learned over twenty years}

The pre-1991 laboratory program for first year students enrolling in Physics 1C at UTS contained experiments that included step by step instructions, encouraged very little independent investigation by students, did not link to any everyday applications of physics, and were out of sequence with concepts or principles introduced and discussed in lectures or tutorials. Bringing students, discipline experts and educational researchers together allowed for an informed critique of the Physics 1C laboratory program. This critical mass of participants with varied backgrounds and understandings of physics and science education was vital as it tapped into diverse and discriminating views essential to the development of a successful inquiry-oriented laboratory program. Strong and enthusiastic leadership dedicated to the development was equally important, 
as it assured the innovation remained a high priority for the DAP until the new program had become established.

Through fortnightly meetings that occurred over a period of approximately 18 months we were able to explore the shortcomings in the current program, and what elements a reconceptualised Physics 1C program should contain. This gestation period allowed a shared vision of the new program to emerge. Without a shared vision of the nature of what is to be achieved, and the means by which it may be achieved, ambitious innovations can easily founder (Hernandez, Ravn, \& Forero-Shelton, 2014). The procedure by which the Physics 1C laboratory program was developed, in which of teams consisting of members with a range of backgrounds and interests collaborated with stakeholders was so successful that it was adopted for the development of the Physical Modelling and Physical Aspects of Nature laboratory programs.

In introducing inquiry-oriented activities for all our first year physics subjects, we chose not to modify existing experiments, but set them aside and in the process discard the associated laboratories manuals. Advantages of this were that we could conceptualise the program as a whole rather than a series of isolated episodes students experience while in the laboratory. We were also able to scaffold the learning experiences throughout the semester, beginning with more guided experiments progressing to situations in which students were given more freedom and responsibility to design and carry out their own experiments. As all students worked on the same experiment in the same laboratory period, we were able to sequence the experiments with material introduced in the lectures, bringing a unity and coherence to the subjects.

The innovations introduced since 1991 were prompted by the literature on learning through inquiry (Tamir, 1991) as well as the teams' recognition of the importance of giving students an 
authentic experience of acting in the role of scientist (Boud et al., 1989). The development process, as embodied in figure 1, matured over time as we learned more about involving stakeholder at all stages. Consistent with the findings of others, we found that active learning, in this case learning through hands-on inquiry, increased student satisfaction and engagement (Ahlfeldt, 2005).

Not all academics within the DAP were involved in developing the new laboratory programs but we understood the importance of having the majority of faculty positively disposed towards the revitalisation of the laboratory programs. To this end whole of department workshops in which the goals of the new laboratory program were explored and new experiments trialled by full time staff did much to get the majority of staff 'on side'. Academics not directly involved with the innovations could bring their perspectives of the new program. Perhaps inevitably there were academics (few in number) who could see little value in changing the programs. The input of such academics was vital as a reality check and for us to ask ourselves 'are we convinced of the value of the approach(es) we are adopting?'.

\section{Supporting student learning}

In the development of new inquiry-oriented experiments we recognised the importance of setting the experiments within contexts that have meaning for students and to which students bring experiences and attitudes to learning and their beliefs about what constitutes learning. These experiences and attitudes can vary enormously, especially in large enrolment first year subjects that include students from many science disciplines. 
It was recognised early that changing the nature of the experiment to include more inquiry required a change in the role and contribution of those supervising the laboratory from instructor to facilitator. Such a change required a shift in the approach to professional development of a strategically important group of individuals. Members of the group going forward would be (on the whole) casual academics, many with study priorities of their own, such as completing a PhD. We introduced demonstrator orientation sessions in which issues that emerge while supporting students learning during an inquiry session could be explored. These sessions were also used to trial new experiments, with the demonstrators as surrogate students. This allowed the demonstrators to become familiar with experiments, examine how they might support student learning when they supervise a class, while at the same time giving feedback as to how the experiment could be improved.

As direct one-on-one interactions between students and demonstrators is largely limited in physics to the laboratory, the extent to which the alignment of the backgrounds, attitudes and experiences of instructors with their students impact on for student learning, engagement and satisfaction deserves to be an area of research (Alkaher \& Dolan, 2011)

\section{Conclusion}

Over two decades ago, the DAP at UTS made a determined move to embed inquiry-oriented activities into the laboratory program for students enrolling in a first year physics subject. Since that time inquiry-oriented activities have been expanded to all first year physics subjects, such that to date of the order of 15,000 students have engaged in such activities at UTS. Our experiences of developing inquiry-oriented experiments as described in this chapter lead us to conclude that: 
- Inquiry-oriented experiments are superior to recipe-based experiment at providing students with experiences that closely imitate the processes of science and the activities of practicing scientists.

- Context and relevance are vital for student engagement and should be built into inquiryoriented experiments. This is especially important for students not intending to major in physics.

- Students expect clears links to be made between their experiments, the wider curriculum and the world outside the laboratory.

- Reforming a laboratory program profits from having a development team with diverse backgrounds and experiences that reaches a common understanding of the purpose of the reform.

Challenges to embedding and sustaining IOL activities have largely been met though the increase in student enrolment means that we must continue to innovate, and most importantly support our demonstrators, as they in turn strive to support student learning through inquiry-oriented activities.

\section{Acknowledgements}

I wish to thank the following people who made major contributions to the design, delivery, evaluation and evolution of the laboratory programs discussed in this paper. David Green, Maree Gosper, Elizabeth Hazel, Sue Johnson, Nirmala Maharaj, Jenny Pizzica, Mark Smith, Lakshmi Srinivasan, Paul Swift and Katrina Waite. I would particularly like pay tribute to the late Bob Cheary. Without his drive and leadership the first year physics laboratory programs at UTS might still be languishing in the mid-20 ${ }^{\text {th }}$ Century. 


\section{References}

American Association of Physics Teachers (1998). Goals of the Introductory Physics Laboratory. American Journal of Physics. 66, 483-485.

Ahlfeldt, S. Mehta, S., \& Sellnow, T. (2005). Measurement and analysis of student engagement in university classes where varying levels of PBL methods of instruction are in use. Higher Education Research and Development, 24(1), 5-20.

Alkaher, A., \& Dolan, W. (2011). Instructors' decisions that integrate inquiry teaching into undergraduate courses: how do I make this fit? International Journal for the Scholarship of Teaching and Learning, 5 (2), 1-24.

Bless, A. A. (1933). Cook-book laboratory work. American Journal of Physics, 1, 88-89.

Boud, D., Dunn, J., \& Hegarty-Hazel, E. (1989). Teaching in laboratories. Milton Keynes, Open University Press.

Boyer Commission on Educating Undergraduates in the Research University (1998).

Reinventing undergraduate education: A blueprint for America's research universities.

Stony Brook, NY: State University of New York-Stony Brook. Retrieved from http://www.niu.edu/engagedlearning/research/pdfs/Boyer_Report.pdf

Cheary, R., Gosper, M.V., Hazel E., \& Kirkup, L. (1995). Revitalising the first-year physics laboratories at the University of Technology, Sydney. Australia \&New Zealand Physicist, $32,119-124$.

Etkina,E., Karelina, A., Ruibal-Villasenor, M., Rosengrant, D., Jordan, R., \& Hmelo-Silver, C. E. (2010). Design and reflection help students develop scientific abilities: learning in introductory physics laboratories. Journal of the Learning Sciences, 19(1), 54-98.

Gosper, M., Cheary, R., Hazel, E., \& Kirkup, L. (1993). Reforming the Physics Laboratory: From Theory to Practice. The Proceedings of the Third International Seminar on Misconceptions 
and Educational Strategies in Science and Mathematics, Misconceptions Trust: Ithaca, NY. Retrieved from http://www.mlrg.org/proc3pdfs/Gosper_Physics.pdf.

Hanif, M., Sneddon, P. H., Al-Ahmadi, F. M., \& Reid, N. (2009). The perceptions, views and opinions of university students about physics learning during undergraduate laboratory work. European Journal of Physics, 30, 85-96.

Healey, M., \& Jenkins, A. (2009). Developing undergraduate research and inquiry. Retrieved from <www.heacademy.ac.uk/assets/documents/resources/publications/ developingundergraduate_final.pdf $>$

Hegarty, E. H. (1978). Levels of scientific enquiry in university science laboratory classes: implications for curriculum deliberations. Research in Science Education, 8, 45-57.

Hernandez, C., Ravn, O., \& Forero-Shelton, M. (2014). Challenges in a physics course: introducing student-centred activities for increased learning. Journal of University Teaching and Learning Practice, 11, (2). Retrieved from:

http://ro.uow.edu.au/jutlp/vol11/iss2/8

Institution of Engineers, Australia (1996). Changing the culture: engineering education into the future. (Barton, Australian Capital Territory: Institution of Engineers, Australia).

Jones, S.M., Yates, B.F., \& Kelder, J-A. (2011). Learning and teaching academic standards project: science learning and teaching academic standards statement. Sydney: Australian Learning and Teaching Council.

Kirkup, L., Johnson, S., Hazel, E., Cheary, R. W., Green, D. C., Swift, P., \& Holliday, W. (1998). Designing a new physics laboratory programme for first year engineering students. Physics Education, 33, 258-265.

Kirkup, L., Pizzica, J., Waite, K., \& Srinivasan, L. (2010). Realizing a framework for enhancing the laboratory experiences of non-physics majors: from pilot to large-scale implementation. European Journal of Physics, 31, 1061-1070. 
Kirkup L., Pizzica J., Waite, K. M., \& Mears A. (2012). Adaptable resource kit. Retrieved from http://www.iolinscience.com.au/wp-content/uploads/2011/11/ARK_June-10_2013.pdf

Lee, V. S. (2011). The power of inquiry as a way of learning. Innovative Higher Education 36, 149-160.

National Curriculum Board (2010). Shape of the Australian Curriculum: Science. Retrieved from $\langle$ www.acara.edu.au/verve/_resources/Shape_of_the_Australian_Curriculum.pdf $>$

Office of the Chief Scientist (2013). Science, Technology, Engineering and Mathematics in the National Interest: A Strategic Approach. Australian Government: Canberra. Retrieved from http://www.chiefscientist.gov.au/wpcontent/uploads/STEMstrategy290713FINALweb.pdf

Pitkethly, A., \& Prosser, M. (2001). The first year experience project: a model for university change. Higher Education Research and Development, 20, 185-198.

Ramsden, P. (2003). Learning to teach in higher education $2^{\text {nd }}$ Edition. Oxford: Routledge.

Schwab, J. J. (1960). Inquiry, the science teacher and the educator. School Review 68, 176-195.

Tamir, P. (1983). Inquiry and the science teacher. Science Education, 67(5), 657-672.

Weaver, G. C., Russell, C. B., \& Wink, D. J. (2008). Inquiry-based and research-based pedagogies in undergraduate science. Nature Chemical Biology 4(10), 577-580.

Welch, W. W., Klopfer, L. E., Aikenhead, G. S., \& Robinson, J. T. (1981). The role of inquiry in science education: analysis and recommendations. Science Education, 65(1), 33-50.

Wenning, C. J. (2005). Minimizing resistance to inquiry-oriented science instruction: The importance of climate setting. Journal of Physics Teacher Online, 3(2), 10-15. 